\title{
Measuring the Multicultural Quotient of a School
}

D. Bruce Sealey

Enough research has been done in multicuitural education so that guidelines can be developed to guide curriculum development at both the local and provincial levels. Six guidelines are presented for considera- tion. Questions arising from the guidelines are posed as examples of how classroom teachers, supervisory personnel or curriculum developers might assess current efforts within their jurisdiction.

The purpose of this article is to delineate six guidelines, arising from research findings, that will serve educators in either planning or evaluating multicultural programs in schools. In addition, it raises a number of questions to guide a teacher or principal in assessing a program or school.

Whether people approve or not, multiculturalism is a fact in Canadian society and therefore must be reflected in our schools. As a people we may be unsure of precisely what we mean when using the word, but a rational analysis of it inevitably leads to the conclusion that the term "multiculturalism" is a misnomer (Roberts \& Clifton, 1982). If one considers culture as the learned behaviours, physical and mental, of a people, then it is obvious that a change from one cultural context to another radically alters behaviour. The policy might better be called multi-ethnic for it encourages a diversity of ethnic expression rather than cultural diversity. There can be little doubt in most people's minds that when cultural groups arrive in Canada, it is impossible for them, with few exceptions, to transfer to their new home the relevant range of social structures needed to perpetuate their original cultures. Canadian institutions, the economic forces and overpowering anglo and franco cultures absorb them. This structural assimilation inevitably, over historical time, leads to cultural assimilation. What is left is not culture, but ethnicity. Ethnicity implies the existence of a sub-culture in which group members feel themselves bound together by common ties (Yetman \& Steele, 1972, p. 12). We have, then, a policy described as "multicultural" when, in fact, we mean "multiethnic." It is a typically Canadian compromise to use a misleading descriptor with which all can be content, for in our country, tradition demands that form take precedence over substance. 
We are a multi-ethnic country in that great masses of the people have a well developed concept of symbolic ethnicity by which we mean "a nostalgic allegiance to the culture of the immigrant generation [and] a love for and pride in a tradition that can be felt without having to be incorporated in everyday behaviour." (Gans, 1980). And this sense of ethnicity, with its emotional symbols, represents a powerful force in Canadian society and in the lives of individuals. We see it in the reaction on some faces at the first sounds of an approaching bagpipe band; the great respect many still accord the Queen; the proudly defiant headgear of the Sikh; King Billy on his white horse leading the Orangemen's parade; the continued use of the Gregorian calendar; the ceinture flèchée at a Metis gathering, and the list is endless. Heartstrings are tugged and emotions are stirred, for good or bad, in countless ways that rise above mere rational thought.

When we use the word "multiculturalism" in our uniquely Canadian inappropriate manner, we attach to the word related and equally inappropriate and rationally unrelated terms such as racism, prejudice and discrimination. We know that culture is not a function of race in a rational sense (Sealey, 1976), but we also know that the folk knowledge of Canadians does not separate them. Therefore, as teachers of children, we accept the garbled bag of meanings and try to do something about the problems that arise in our classrooms. We have all been trained in a university setting and, as rational people, have learned the sad lesson that there is nothing as irrational as those people who believe that rationality rules our society.

Even though the totality of our society may be irrational, teachers firmly believe that the ultimate aim should be to develop a decisionmaking process that is based on rationality. One aspect of that rationality is that we base what we do in education on research findings. And this is what bothers me most about what is happening in regard to multicultural education. The attempts at curricular adaptation strike one as akin to the hero of one of Stephen Leacock's short stories in which at the climax the man leaped on his horse and "rode off madly in all directions." There are people who have carefully researched some of the problems associated with multicultural education, and curriculum developers at the local and provincial levels should heed their research findings and thus avoid riding off madly in all directions.

There are six guidelines, solidy based on research findings, that should be of value to schools planning on evaluating multicultural programs:

1. Teach students to accept cultural diversity as the norm (Kehoe, 1981). Canada, dedicated to a policy of multiculturalism, has laid upon teachers the difficult but challenging task of helping the young to be aware of, and sensitive to, the multiplicity of ethnic groups within its borders. Canada 
has become a multiracial, multi-ethnic nation, nestled, albeit uncomfortably at times, within a bilingual framework, and is bound to experience tensions and conflicts as the different groups interact. For we are all ethnocentric and believe that our ways of doing things are most appropriate and, thus, the most likely to lead society to happiness and selffulfillment. Each group secretly believes that if others would become like it, the country would be an ideal place in which to live.

Teachers are charged with the task of helping young people to rid themselves of the notion that if people would just get to know one another they would be friends and all would be well. This simplistic notion is as dangerous as it is sentimental. The fact is that we must learn to get along with people who are different culturally, physically, and in their patterns of behaviour, for they are likely to stay that way for a long time. In short, we must learn to get along with them whether we like them or not. One of the ways we can do this is to teach the origins of cultural diversity (Ijaz, 1982). It is not enough to know that people are different, but rather our teaching must help students to understand why those differences are there. Such an approach would demand a dramatic restructuring of the Social Studies curriculum, for the present one emphasizes "what is or was" rather than "why it is or was."

2. Emphasize cultural similarities rather than differences (Kehoe \& Ungerleider, 1979). Many multicultural programs launched in schools have emphasized differences and research has shown that this tends to increase negative feelings among students. Many teachers equate values with their manifestations; that is, customs. We see the burial customs of some Ojibway, who build houses over their graves rather than placing gravestones, and marvel at the differences. We tell students of a people who bury their dead in a vertical rather than a horizontal position, and marvel once again. We examine the quaint custom of placing food offerings at the grave of the departed and at the exotic idea of worshipping ancestors and marvel at how different we are. Yet the values behind these diverse customs are similar; we all honour our departed. How we express or manifest the common value is really unimportant. Too often, however, we forget the similarity of the values and stress that which is insignificant, the manifestation of them.

3. Emphasize student involvement in multicultural learning (Ijaz, 1982). Research has shown that student participation rather than the formal lecture is more likely to bring about a change in attitude. Role playing, where students assumed roles in the other culture so that they experienced the other group personally, has proven very effective in changing attitudes (Licher \& Johnson, 1969). 
4. Strive for intimate and quality contact with members of different ethnic groups (Ijaz \& Ijaz, 1982). Research has found that there is little effect on the ethnic attitudes of students as a result of academic instruction about prejudice (lectures, reading books, answering questions, writing essays). In one research study there was an increase in prejudice (McNeil, 1960). Field trips and community members invited into the classroom have been vindicated as a teaching method. Is it not nice to learn that research has proven what every good teacher has always known? It does seem a bit obvious that if you want to establish a positive image in the mind of a student about something, you don't call in the local drunk to represent the ethnic group. Nevertheless, the research lesson is important. You do not invite into your classroom a member of the ethnic minority who spends his time telling students what a fine group he belongs to and thereby implying that all others are somehow lesser mortals.

5. Teachers should work hard at reducing the level of bigotry of their students. This is, of course, only possible if the teachers can lower their own level of bigotry. Let me note at this point that bigotry is one of those sadly degraded and misunderstood words in the English language. To be a bigot describes someone who adheres to one idea to the exclusion of all others. In the teaching profession we have bigots who believe "open areas" are superior to "closed classrooms"; " $x$ " reading system is superior to "y"; "corporal punishment" is to be preferred over "psychological control." Bigots live in a black and white world and belief in one thing forever excludes others. We find the same attitudes among our students. Their way is right so why should not other people be forced to conform? This is a most human reaction to any question or problem. But it can be modified as evidenced by the work of researchers (Kehoe \& Ungerleider, 1979).

6. Teachers should work to create a multicultural tone in the school and classroom (Ziegler, 1981) This cannot be done unless the staff is convinced that multiculturalism is both a possible and desirable aim for itself and Canadian society.

\section{WHAT IS YOUR SCHOOL'S MULTICULTURAL QUOTIENT?}

Keeping in mind the six guidelines which research results have indicated teachers should follow, how would we rate the school in which we work? A stroll through a school, coupled with brief chats with teachers, allows one to gain a quick impression of what is happening.

The Staff. Does the staff attempt to sensitize itself to the implications of 
our multicultural policies? Have any part of recent in-services been spent on multiculturalism and its implications for what teachers must do? Is there a small multicultural committee whose task is to generate ideas for recommendations to the entire staff? Perhaps it seeks to know the special days of the ethnic groups the school serves. We need to interweave their festival days and traditions into the existing ones that are almost totally British and French and Christian. This committee might also have the task of updating information on multicultural materials useful to classroom instruction and making this information available to others. Its contacts with ethnic organizations might generate a list of speakers willing to come to the school on special occasions. Is any thought being given to the need, or desire, for minority language classes?

The Library. Do we see efforts made to include novels, poetry, biography, etc., of the diverse people of Canada? Does the audio-visual section do likewise? Is the librarian keeping in close contact with the multicultural committee and seeking its advice on new materials to purchase? Do the library displays reflect aspects of multiculturalism?

The Gymnasium. Would a chat with the teachers reveal that an effort is made to introduce a variety of games other than those traditionally played? Are they sensitive to the fact that some of the immigrant children hold different views of the semi-nudity which is a necessary aspect of change rooms? Are they aware that not all cultural groups see the slim, trim athletic body desired by Canadian society as ideal? Or that parents may resent the girls playing games traditionally played by boys?

Music and Art. Would we find the curricula of these subjects representing threads of the traditions brought to the country by groups other than British and French? Of all subjects in the school these are, by their very nature, the most international. Yet they have become over the generations extremely narrow in their content. The new emphasis on multiculturalism may breathe new life into them.

Home Economics. Once again, we would hope to find a broadening of the content of the curriculum. Would we find in food classes that students are introduced to the foods and traditions of food preparation of other countries? In clothing would we find other styles being investigated? In the child care program is there an attempt to compare and contrast differing approaches or are students taught only one way, with the implication that all others are of less worth?

The Classroom. For purposes of observations in the academic classroom, one might consider three categories: (a) physical, (b) the formal curriculum, and (c) the informal curriculum. 
(a) Physical

Here one would check the pictures on the walls, work on the bulletin board, books on shelves, completed and on-going projects. Would there be a tone in the physical set-up of the classroom that indicated cultural diversity?

(b) The formal curriculum

In what ways is the teacher trying to make Social Studies an exercise in multiculturalism? Are there separate units on various ethnic groups or is an integrated approach taken? What efforts are made to deal with recent immigrants who may have language problems? Are the students deliberately grouped to encourage cross-cultural contacts? Depending upon the grade level are the facts of race taught? Students should learn the "why" of differences in skin colour, hair texture, head shapes, etc. Students should be encouraged to ask questions about physical as well as cultural differences and their questions should be answered. "Why do Tim Wong's eyes look different from mine?" for example, is a legitimate question for any child. Three journals, The History and Social Science Teacher, Multiculturalism, and Integrated Education, are filled with excellent ideas for teachers in multicultural situations. A recent monograph by Roe (1982) gives an excellent review of what various schools across Canada are doing.

\section{(c) The informal curriculum}

This intrinsic part of a school and a classroom is a vital part of any education system. How we teach is as important as what we teach. Respect, consideration, compassion and understanding for all students is crucial. We are all ethnocentric to a degree but, as teachers, we must try to reduce it. We are all prejudiced to a degree, but we should try not to show it. Even if we cannot entirely rid ourselves of prejudice we must never let our thoughts be translated into actionwhich is discrimination. Our every action and word sets the tone of the classroom which is absorbed by the students even when they fight against it.

Understanding the long range impact of male sexist language upon the subliminal thinking of girls, we try to be non-sexist in our speech. Respect for another religion precludes our asking a Moslem child to write his Christian name on an assignment. The growing religious diversity of the country means I must give attention to holy days other than those Christian ones in my own tradition. Likewise, I must acknowledge other festivals besides those I have enjoyed in my life. To become a good citizen in a country, newly dedicated to becoming multicultural, is not easy. It disrupts the old, well known and understood traditions with which many 
of us are so comfortable.

Yet we must change, for that is the direction our leaders have legislated for us. Like the French "problem," multiculturalism has to be faced up to by individuals and groups. And this is one of our problems. Multiculturalism in schools cannot be just for those schools having students from mixed backgrounds and traditions. More and more as adults we leave our home community and mix in large urban centres with others, so the school must prepare all children to live in an increasingly multicultural country. We must teach children to be much more accepting of physical and cultural differences. They have to learn to get along with other people whether they like them or not.

It is wrong to allow a school or a teacher to stress one or two groups in school studies. The totally Anglo-Saxon, Mennonite, Indian, Metis, Ukrainian communities must be as deeply exposed to multiculturalism as those which are mixed communities. Anything less than a total effort on the part of the school systems across Canada is liable to result in Canada experiencing the terrible social conflicts happening in many other countries around the world.

Following this brief and informal survey of your school, take the information collected and place it under the six guidelines research tells us are most likely to bring about effective multicultural programs. If your multicultural quotient is low, you may discover that some guidelines have few or no points listed under them. This "snapshot" picture of your school may indicate areas where improvements are badly needed-either in what might be done or where ineffective activities are being undertaken.

\section{REFERENCES}

Gans, H. Symbolic ethnicity: The future of ethnic groups and cultures in America. Ethnic and Racial Studies, 1980, 2.

Ijaz, M.A. Can we change our students' racial attitudes? Orbit, 1982, 13(1), 19-22. Ijaz, M.A., \& Ijaz, H.I. We can change our children's racial attitudes. Multiculturalism, 1982, 5 (2), 11-17.

Kehoe, J.W. Effective tools for combatting racism in the school. Multiculturalism, 1981, 4 (3), 3-10.

Kehoe, J.W. \& Ungerleider, C.C. The effects of role exchange, questioning and empathetic perceptiveness. Alberta Journal of Educational Research, 1979, 25 (1), 48-52.

Licher, J.H. \& Johnson, D. Change in the attitudes towards Negroes of white elementary school students after use of a multi-ethnic reader. Multiculturalism, $1982,5(2)$.

McNeil, J.D. Changes in ethnic reaction tendencies during high school. Journal of Educational Research, 1960, 53 (5), 199-200. 
Roberts, L.W. \& Clifton, R.A. Exploring the ideology of Canadian multiculturalism. Canadian Public Policy, 1981, 8 (1).

Roe, M. Multiculturalism, racism, and the classroom. Toronto: Canadian Education Association, 1982.

Sealey, D.B. Race, culture and education. Manitoba Journal of Education. 1976, 10 (2), 3-10.

Ziegler, S. Maximizing the potential of multiculturalism in the classroom. Education Canada, 1981, 21 (2), 12-16.

\section{THE AUTHOR}

D. Bruce Sealey is a professor at the Faculty of Education, University of Manitoba. He teaches in the area of Cross-cultural Studies and also serves as a Consultant to Police Forces and other groups dealing with ethnic minorities. His books include The Métis: Canada's Forgotten People and three edited volumes, The Other Natives: The Métis (with A.S. Lussier). He has written extensively for teachers and published numerous textbooks for public school use. 